\title{
Resistência microbiana a antibióticos: quo vadis?
}

\author{
Microbial resistance to antibiotics: quo vadis?
}

\author{
Anselmo Gomes de OLIVEIRA; \\ Dâmaris SILVEIRA \\ Editores-chefe
}

O mundo, como sociedade globalizada, enfrenta uma crise sem precedentes com relação a resistência microbiana a antibióticos. O desenvolvimento natural de resistência, por fungos, bactérias, vírus e outros parasitas é um fenômeno essencial para a sobrevivência desses organismos. Foram as décadas de uso irracional e de prescrições descontroladas e excessivas, inclusive dos antibióticos mais antigos e tradicionais (considerados de primeira linha), que levaram à situação desastrosa do momento. As infecções resistentes a antibióticos têm causado cerca 700 mil mortes anuais no mundo (1), cerca de 35 mil nos EUA (2) e, no Brasil, cerca de 23 mil (3).

O problema vem sendo tratado de forma incisiva por órgãos como a Organização Mundial da Saúde (OMS) e a Organização das Nações Unidas (ONU). A ONU instituiu em 2019, a Coordenação Interagencial sobre Resistência Antimicrobiana (IAGC)", a qual elaborou um relatório completo para a Secretaria Geral da ONU recomendações para o enfrentamento do problema (4) A OMS prioriza a tuberculose para tratamento, pelas 1,8 milhões de mortes anuais totais, das quais $230 \mathrm{mil}$ decorrentes de bactérias multirresistentes (5). A estratégia brasileira, para a abordagem do assunto se iniciou com a RDC 44/2010 da Agência Nacional de Vigilância Sanitária (Anvisa), tornando obrigatória a retenção das prescrições na aquisição de antibióticos como forma de controle do uso inadequado (6), e a publicação, em 2019, do Plano Nacional de Prevenção e Controle da Resistencia aos antimicrobianos, pelo Ministério da Saúde (7), atualizado em agosto de 2021. O documento baseia-se em algumas estratégias para o período de 2018-2022, que incluem a conscientização sobre a resistência de microrganismos aos antimicrobianos, a melhoria da base científica sobre o assunto, por meio de vigilância e pesquisa, ações para a redução da incidência de infecções, a otimização no uso racional de medicamentos antimicrobianos na saúde, implementação de novas terapias e métodos diagnósticos para o tratamento de infecções, além da prevenção, por meio de vacinas.

Mesmo antes do início da pandemia de COVID-19, o mundo experimentava os problemas da incômoda situação da resistência a antimicrobianos. Contudo, o uso indiscriminado de medicamentos, mesmo sem eficácia contra o vírus SARS CoV-2 - inclusive antibióticos - levou a um alerta global quanto à possibilidade de aumento da disseminação da resistência microbiana, criando superbactérias resistentes aos tratamentos disponíveis (8). De fato, alguns especialistas têm discutido que o aumento da resistência a antimicrobianos pode ser considerada um dos efeitos colaterais da COVID-19 (9-11).

Infecções exigem respostas rápidas, tanto no que se refere à prevenção quanto ao tratamento. Entretanto, a pesquisa por um novo antibiótico pode envolver cerca de 2,6 bilhões de dólares decorrentes do balanço entre os sucessos e fracassos ao longo do desenvolvimento (5). As ações mundiais para minimizar o problema passam por intervenções e incentivos globais, a extensão do tempo de exclusividade para de antibióticos para recuperação de investimentos e a criação de programa de formação estoques para os antibióticos críticos (1), além do preenchimento de lacunas no financiamento e para o desenvolvimento de antibióticos e tratamentos inovadores, por exemplo, a coalizão de algumas 
farmacêuticas filantrópicas e o Banco Europeu de Desenvolvimento, com apoio da OMS, visando garantir o financiamento do desenvolvimento de produtos inovadores (1).

Os antibióticos representam um aspecto vulnerável para a cobertura e segurança de saúde mundial, sendo necessário um esforço global com mecanismos de financiamento, para atender as reais necessidades dessa ameaça. Por esses motivos a OMS promove anualmente a Semana Mundial de Conscientização Antimicrobiana como forma de incentivar as melhores práticas para o público em geral, profissionais de saúde e legisladores visando minimizar o surgimento e disseminação de infecções resistentes a medicamentos (12).

Contudo, a redução da ocorrência de resistência a antibióticos deve ser encarada como uma ação conjunta, envolvendo órgãos públicos com políticas acertadas a respeito de um assunto tão sério, a educação/informação de profissionais da área da Saúde e usuários do medicamento quanto os riscos do uso indiscriminado de antibióticos e a conscientização desses profissionais, com ênfase nos farmacêuticos comunitários sobre a necessidade da orientação correta do usuário do medicamento quanto à automedicação.
1. ONU. Relatório da ONU pede ação urgente para evitar crise de resistência antimicrobiana: Organização das Nações Unidas; 2019 [Available from: https://news.un. org/pt/story/2019/04/1669901.

2. CDC. Antibiotic/Antimirobial resistance: Centers of Disease Control and Prevention; 2020 [Available from: https://www.cdc.gov/drugresistance/index.html.

3. Zagui GS. Avaliação da multirresistência a antibióticos e produção de ESBL e carbapenemases em bacilos gram-negativos de efluente hospitalar e urbano. Ribeirão Preto: Universidade de São Paulo; 2020.

4. IACG. No time to wait: Securing the future from drugresistant infections. Interagency Coordination Groupon Antimicrobial Resistance; 2019.

5. WHO. Antibacterial agents in clinical development: an analysis of the antibacterial clinical development pipeline. Genebra: World Health Organization; 2019.

6. BRASIL. Dispõe sobre o controle de medicamentos à base de substâncias classificadas como antimicrobianos, de uso sob prescrição médica, isoladas ou em associação e dá outras providências, (2010).

7. BRASIL. Plano de ação nacional de prevenção e controle da resistência aos antimicrobianos no âmbito da saúde única 2018-2022 (PAN-BR). Brasilia: Ministerio da Saaúde; 2019. 28 p.
8. ANVISA. Pandemia pode aumentar o risco de resistência microbiana: Agencia Nacional de Vigilância Sanitária; 2020 [Available from: https://www.gov.br/anvisa/pt-br/ assuntos/noticias-anvisa/2020/pandemia-pode-aumentaro-risco-de-resistencia-microbiana.

9. Razzaque MS. Exacerbation of antimicrobial resistance: another casualty of the COVID-19 pandemic? Exp Rev Anti-infective Ther 2021;19(8):967-71. DOI: 10.1080/ 14787210.2021 .1865802

10. Mazumder P, Kalamdhad A, Chaminda GGT, Kumar M. Coalescence of co-infection and antimicrobial resistance with SARS-CoV-2 infection: The blues of post-COVID-19 world. Case Studies in Chemical and Environ Enginer. 2021;3:100093. DOI: 10.1016/j.cscee. 2021.100093

11. Lobie TA, Roba AA, Booth JA, Kristiansen KI, Aseffa A, Skarstad K, et al. Antimicrobial resistance: A challenge awaiting the post-COVID-19 era. Int J Infectious Dis. 2021;111:322-5. 10.1016/j.ijid.2021.09.003

12. WHO. World Antimicrobial Awareness Week. 18-20 november 2020: World Health Organization; 2020 [Available from: https://www.who.int/campaigns/worldantimicrobial-awareness-week/2020. 